\title{
Desflurane inhalation before ischemia increases ischemia-reperfusion-induced vascular leakage in isolated rabbit lungs
}

\author{
Yoshiaki Oshima*, Seiji Sakamoto, Kazumasa Yamasaki, Shinsuke Mochida, Kazumi Funaki, Naoki Moriyama, \\ Akihiro Otsuki, Ryo Endo, Masato Nakasone, Shunsaku Takahashi, Tomomi Harada, Yukari Minami \\ and Yoshimi Inagaki
}

\begin{abstract}
Background: Isoflurane and sevoflurane protect lungs with ischemia-reperfusion (IR) injury. We examined the influence of desflurane on IR lung injury using isolated rabbit lungs perfused with a physiological salt solution.

Methods: The isolated lungs were divided into three groups: IR, desflurane-treated ischemia-reperfusion (DES-IR), and ventilation/perfusion-continued control (Cont) groups ( $n=6$ per group). In the DES-IR group, inhalation of desflurane at 1 minimum alveolar concentration (MAC) was conducted in a stable 30-min phase. In the IR and DES-IR groups, ventilation/perfusion was stopped for $75 \mathrm{~min}$ after the stable phase. Subsequently, they were resumed. Each lung was placed on a balance, and weighed. Weight changes were measured serially throughout this experiment. The coefficient of filtration $\left(\mathrm{K}_{\mathrm{fc}}\right)$ was determined immediately before ischemia and $60 \mathrm{~min}$ after reperfusion. Furthermore, bronchoalveolar lavage fluid (BALF) was collected from the right bronchus at the completion of the experiment. After the completion of the experiment, the left lung was dried, and the lung wet-to-dry weight ratio (W/D) was calculated.

Results: The $\mathrm{K}_{\mathrm{fc}}$ values at $60 \mathrm{~min}$ after perfusion were $0.40 \pm 0.13 \mathrm{ml} / \mathrm{min} / \mathrm{mmHg} / 100 \mathrm{~g}$ in the DES-IR group,

$0.26 \pm 0.07 \mathrm{ml} / \mathrm{min} / \mathrm{mmHg} / 100 \mathrm{~g}$ in the IR group, and $0.22 \pm 0.08$ (mean $\pm \mathrm{SD}$ ) $\mathrm{ml} / \mathrm{mmHg} / 100 \mathrm{~g}$ in the Cont group. In the DES-IR group, the $K_{\mathrm{fc}}$ at 60 min after the start of reperfusion was significantly higher than in the other groups. In the DES-IR group, W/D was significantly higher than in the Cont group. In the DES-IR group, the BALF concentrations of nitric oxide metabolites were significantly higher than in the other groups. In the DES-IR group, the total amount of vascular endothelial growth factor in BALF was significantly higher than in the Cont group.
\end{abstract}

Conclusions: The pre-inhalation of desflurane at 1 MAC exacerbates pulmonary IR injury in isolated/perfused rabbit lungs.

Keywords: Desflurane, Ischemia-reperfusion injury, Isolated rabbit lungs, Coefficient of filtration

\section{Background}

Many studies reported that volatile anesthetics play a protective role against myocardial ischemia-reperfusion injury. The cardioprotective actions of these anesthetics are stated in the "ACC/AHA Guidelines for Perioperative Cardiovascular Assessment and Management after

*Correspondence: yoshimatomo@gmail.com

Division of Anesthesiology and Critical Care Medicine, Department of Surgery, Tottori University Faculty of Medicine, 36-1 Nishi-cho, Yonago, Tottori 683-8504, Japan
Non-cardiac Surgery" (Fleisher et al. 2007). Some articles have also reported the protective actions of volatile anesthetics against pulmonary ischemia-reperfusion injury (Liu et al. 1999, 2000).

Ischemia-reperfusion injury of the organs occurs through anoxia-reoxygenation. Anoxia rapidly decreases the level of adenosine triphosphate (ATP), leading to the generation of hypoxanthine. Reoxygenation promotes the production of reactive oxygen species, such as superoxide, hydrogen peroxide, and hydroxyradicals 
by hypoxanthine, inducing organ injury (de Perrot et al. 2003; Janero et al. 1991; Ambrosio et al. 1991).

In the lungs, the alveoli contain oxygen; therefore, oxygen deficiency does not occur rapidly. In the cardiac muscle, ATP level decreases to 50\% within 6 min after circulatory arrest (Kolocassides et al. 1995). For lung tissue inflated with room air, $1.5 \mathrm{~h}$ are required until the ATP level decreases to $50 \%$ despite circulatory arrest (De Leyn et al. 1993). The pathogenesis of pulmonary ischemia-reperfusion injury differs from that of cardiac ischemia-reperfusion injury. Briefly, pulmonary blood flow disruption stimulates mechanoreceptors of the pulmonary vascular endothelial cells, causing lung injury through lipid peroxidation in these cells (de Perrot et al. 2003).

Lung tissue is more complex than cardiac muscle, consisting of the vascular endothelium and alveolar epithelium (de Perrot et al. 2003; Egan 2004). Pulmonary ischemia-reperfusion injury refers to damage of the pulmonary vascular endothelium and alveolar epithelium. Alveolar macrophages activated in the presence of ischemia-reperfusion release inflammatory cytokines (de Perrot et al. 2003). The influence of volatile anesthetics on pulmonary and cardiac ischemia-reperfusion injury may differ.

In a rat experimental model of neurogenic pulmonary edema, isoflurane exacerbated pulmonary edema by inducing the release of vascular endothelial growth factor (VEGF) in the vascular endothelium (Kandatsu et al. 2005); neurogenic pulmonary edema was caused by sympathetic excitement. Desflurane has a chemical formula similar to that of isoflurane (Eger 1987), but it has more potent stimulatory effects on the sympathetic nerve than isoflurane (Weiskopf et al. 1994). In addition, the blocked thoracic aorta causes oxidative stress in the entire organism through ischemia and subsequently pulmonary vascular permeability, which is exacerbated by desflurane (Nielsen et al. 1998). In addition, in pigs under mechanical ventilation, desflurane (1 minimum alveolar concentration $[\mathrm{MAC}]$ ) inhalation caused oxidative stress in the lungs and induced the apoptosis of lung cells (Allaouchiche et al. 2001; Kalimeris et al. 2011). In the present study, we hypothesized that desflurane could exacerbate increased vascular permeability in ischemic reperfusion injured lungs through sympathetic stimulatory effects, and examined this hypothesis using isolated perfused rabbit lungs. Vascular hyperpermeability was evaluated based on the capillary coefficient of filtration $\left(\mathrm{K}_{\mathrm{fc}}\right)$.

\section{Methods}

\section{Isolated perfused lung preparation}

The experimental protocol was approved by the Tottori University Laboratory Animal Care Committee. Isolated rabbit lungs were prepared using the method described in detail by Liu et al. (1999) with minor modifications. Male New Zealand White rabbits weighing 1.9-2.6 kg were used. The lungs were ventilated with $93.5 \%$ air and $6.5 \% \mathrm{CO}_{2}$ (tidal volume $6 \mathrm{ml} / \mathrm{kg}$; frequency $40 / \mathrm{min}$; positive end-expiratory pressure $2 \mathrm{cmH}_{2} \mathrm{O}$ ) and perfused with bicarbonate-buffered physiologic salt solution [PSS (in $\mathrm{mM}$ ): $\mathrm{NaCl}, 119 ; \mathrm{KCl}, 4.7 ; \mathrm{MgSO}_{4}, 1.17 ; \mathrm{NaHCO}_{3}$, 22.61; $\mathrm{KH}_{2} \mathrm{PO}_{4}, 1.18 ; \mathrm{CaCl}_{2}, 3.2$ ] in a recirculating manner at a constant flow rate of $30 \mathrm{ml} / \mathrm{kg} / \mathrm{min}$. To each $100 \mathrm{ml}$ of PSS stock solution, we added $100 \mathrm{mg}$ dextrose, $20 \mathrm{mU}$ insulin, and $5 \mathrm{~g}$ hydroxyethylstarch (Ajinomoto Pharmaceuticals, Tokyo, Japan). Pulmonary arterial pressure $\left(\mathrm{P}_{\mathrm{PA}}\right)$, left atrium pressure $\left(\mathrm{P}_{\mathrm{LA}}\right)$, and airway pressure $\left(\mathrm{P}_{\mathrm{AW}}\right)$ were monitored continuously via side ports in the respective cannula. The partial pressure of carbon dioxide $\left(\mathrm{PCO}_{2}\right)$ in the perfusate was adjusted to $35-40 \mathrm{mmHg}$ during the experiment by continuous aeration of the reservoir liquid surface using mixed gas with the same composition as the inspired gas. The empyreal part of the reservoir was covered with Saran $\mathrm{Wrap}^{\circledR}$, and the liquid surface of the reservoir was separated from air. Gas analysis of the perfusate was performed during the experiment, and a small amount of sodium bicarbonate was added to the perfusate to maintain the $\mathrm{pH}$ at 7.35-7.45.

The lungs were removed en bloc and enclosed in a humidified chamber which was positioned on an electronic scale (GX4000; A and D, Tokyo, Japan) to allow continuous monitoring of lung weight. $\mathrm{P}_{\mathrm{LA}}$ was set at $2 \mathrm{mmHg}$ (referenced at the hilum), and the whole system was equilibrated at $37^{\circ} \mathrm{C}$. A flow probe (FF-050T; Nihon Kohden, Tokyo, Japan) connected to an electromagnetic flow meter (MFV-3100; Nihon Kohden, Tokyo, Japan) was placed in the perfusion circuit for the continuous monitoring of blood flow (Q). Total pulmonary vascular resistance $\left(R_{t}\right)$ was calculated using the following formula: $\mathrm{R}_{\mathrm{t}}=\left(\mathrm{P}_{\mathrm{PA}}-\mathrm{P}_{\mathrm{LA}}\right) / \mathrm{Q}$.

\section{Coefficient of filtration}

Pulmonary vascular permeability was evaluated by determining the pulmonary capillary $\mathrm{K}_{\mathrm{fc}}$ in accordance with the Starling equation (Drake et al. 1978). First, isogravimetric pressure $\left(\mathrm{P}_{\mathrm{ISO}}\right)$ was measured as described by Thompson et al. (1997): the shunt between the pulmonary and left atrial cannulae was opened and perfusion was discontinued, and changes in lung weight were observed by gradually increasing the reservoir height and pulmonary capillary pressure $\left(\mathrm{P}_{\mathrm{PC}}\right)$ to determine maximum $P_{P C}$ without any increase in lung weight, i.e. $P_{I S O}$. The $\mathrm{P}_{\mathrm{PC}}$ was then changed to equal $\mathrm{P}_{\mathrm{ISO}}+7 \mathrm{mmHg}$ by rapidly elevating the reservoir to a height corresponding to $+7 \mathrm{mmHg}$, and the reservoir was kept at this height for $7 \mathrm{~min}$. The rate of lung weight gain every minute from 
2 to 6 min was then recorded on a semilogarithmic plot and extrapolated to time 0 by linear regression. The logarithm of lung weight gain at time 0 was converted to an antilog, and the resulting value was used to calculate $\mathrm{K}_{\mathrm{fc}}$.

$\mathrm{K}_{\mathrm{fc}}$ was normalized using the baseline wet lung weight and expressed in $\mathrm{mL} / \mathrm{min} / \mathrm{mmHg} / 100 \mathrm{~g}$ lung tissue. The baseline wet lung weight was calculated from the body weight (BW) of the animals using the formula: BW (g) $\times 0.0024$ (Seeger et al. 1986).

Although positive pressure ventilation was interrupted during the $\mathrm{K}_{\mathrm{fc}}$ determination, a constant flow of the mixed gas was administered at $3 \mathrm{cmH}_{2} \mathrm{O}$ of $\mathrm{P}_{\mathrm{AW}}$.

\section{Wet-to-dry weight ratio}

The left lung was excised at the end of the experiment and its wet weight was measured. The left lung was dried at $85^{\circ} \mathrm{C}$ under a heating lamp for $30 \mathrm{~h}$ and its dry weight was measured to determine lung water weight compared with pulmonary tissue weight to determine the wet-todry weight ratio (W/D) using the formula: $\mathrm{W} / \mathrm{D}=$ (wet weight - dry weight)/dry weight.

\section{Bronchoalveolar lavage fluid analysis}

The right lung was used for BALF preparation at the end of the experiment. Four aliquots $(5 \mathrm{ml}$ each) of isotonic sodium chloride solution were instilled separately through the trachea and drained. The collected fluid was centrifuged immediately at $250 \times g$ and $4{ }^{\circ} \mathrm{C}$ for $10 \mathrm{~min}$. The supernatant was divided into several aliquots and stored at $-80{ }^{\circ} \mathrm{C}$ until analysis.

The concentration of nitric oxide (NO) metabolites (sum of $\mathrm{NO}_{3}{ }^{-}$and $\mathrm{NO}_{2}{ }^{-}$) was determined using a highperformance liquid chromatography system (Shimadzu, Tokyo, Japan) with visible light absorbance detection at $546 \mathrm{~nm}$, as described by Green et al. (1982).

Lactate dehydrogenase (LDH) concentration was measured using a clinical chemistry analyzer (JCA-BM8060, Japan Electron Optics Laboratory, Tokyo, Japan). The lower detection limit was $6 \mathrm{IU} / \mathrm{l}$.

Superoxide dismutase (SOD) activity was measured by the modified nitrite method, as described by Oyanagui (1984).

Interleukin (IL)-6 concentration was measured using a fully automated chemiluminescent enzyme immunoassay system (Lumipulse F, Fujirebio Inc., Tokyo, Japan). The lower detection limit was $0.2 \mathrm{pg} / \mathrm{ml}$.

VEGF concentration was measured using an enzyme immune assay (EIA) kit (hVEGF QKit, R\&D Systems Inc., Minneapolis, USA). As the concentration of VEGF in BALF reduces through a pulmonary edema fluid-related dilutional effect, we compared the total amount of VEGF in each BALF sample (Cross and Matthay 2011; Bhargava and Wendt 2012; Ware et al. 2005).

\section{Experimental protocol}

The isolated lungs selected were those that (1) had a homogenous white appearance without signs of hemostasis or edema formation, and (2) were isogravimetric in the equilibration period of $30 \mathrm{~min}$.

The isolated lungs were divided into three groups. In the control (Cont) group $(n=6)$, the isolated lungs were continuously perfused and ventilated after an equilibration period for $135 \mathrm{~min}$. In the ischemia-reperfusion (IR) group $(n=6)$, ventilation and perfusion were interrupted (ischemia) after an equilibration period for $75 \mathrm{~min}$, and the isolated lungs were maintained in the humidified chamber at $37{ }^{\circ} \mathrm{C}$ while $\mathrm{P}_{\mathrm{AW}}$ was maintained at $3.5 \mathrm{cmH}_{2} \mathrm{O}$ by administrating a constant flow of mixed gas. Gas at the same concentration and flow rate as used in the equilibration period was added to the liquid surface of the reservoir. The empyreal part of the reservoir was covered with Saran Wrap ${ }^{\circledR}$, and the liquid surface of the reservoir was separated from the air. The pulmonary arterial and left atrial cannula were both opened to the atmosphere, resulting in an intravascular pressure of $0 \mathrm{mmHg}$ during ischemia. The isolated lungs were reperfused and reventilated for $60 \mathrm{~min}$ after ischemia. The flow velocity at the start of reperfusion was increased slowly to $30 \mathrm{ml} / \mathrm{kg} / \mathrm{min}$, so that the $\mathrm{P}_{\mathrm{PA}}$ did not exceed $20 \mathrm{mmHg}$. At the start of reventilation, the positive endexpiratory pressure was established as $10 \mathrm{cmH}_{2} \mathrm{O}$ for a few respirations until atelectasis was macroscopically relieved, but the same respiratory conditions as adopted in the equilibration period were used thereafter. In the desflurane-treated ischemia-reperfusion (DES-IR) group $(n=6), 1$ MAC $[1 \mathrm{MAC}=8.9 \%$ for rabbits (Loer et al. 1995)] desflurane was administered for $30 \mathrm{~min}$ during the equilibration period, then ischemia was performed for $75 \mathrm{~min}$, followed by $60 \mathrm{~min}$ reperfusion and reventilation, which was the same as that for the IR group.

In a preliminary experiment, the pre-inhalation of desflurane at 1.5 MAC was performed. At the start of reperfusion, edema fluid appeared in a tracheal tube before the flow rate reached $30 \mathrm{ml} / \mathrm{kg} / \mathrm{min}$, and it was impossible to continue the protocol. In this experiment, the inhalation concentration of desflurane was established as $1 \mathrm{MAC}$.

Desflurane (Baxter International Inc., Chicago, IL) was administered using a desflurane vaporizer (D-Vapor, Dräger Medical GmbH, Lübeck, Germany). The concentration of desflurane in inspired gas was monitored using a bedside monitor (BSM-2301, Nihon Kohden, Tokyo, Japan).

$\mathrm{K}_{\mathrm{fc}}$ was determined in the IR and DES-IR groups at baseline (end of the equilibration period) and $60 \mathrm{~min}$ after the start of reperfusion. $R_{t}, P_{A W}$, and lung weight gain were determined in the IR and DES-IR groups at baseline and at 10, 20, 30, 40, 50, and $60 \mathrm{~min}$ after the 
start of reperfusion. These values were determined in the Cont group at the same intervals. When edema fluid appeared in a tracheal tube before the flow velocity reached $30 \mathrm{ml} / \mathrm{kg} / \mathrm{min}$ at the start of reperfusion, the $\mathrm{K}_{\mathrm{fc}}$ and wet left lung weight were measured at that point, and BALF was collected from the right lung. The experiment was then completed.

Statistical analysis was performed using Prism 5 (Graph Pad Software, San Diego, CA). All data are presented as the mean \pm standard deviation (SD). Changes in $\mathrm{K}_{\mathrm{fc}}, \mathrm{R}_{\mathrm{t}}$, lung weight gain, and $\mathrm{P}_{\mathrm{aw}}$ were evaluated using two-way factorial analysis of variance (ANOVA) followed by the post hoc Bonferroni test. Changes in NO metabolites, LDH, SOD, IL6, and VEGF in the BALF and the $\mathrm{W} / \mathrm{D}$ were evaluated using one-way factorial ANOVA or Kruskal-Wallis test followed by post hoc Tukey test or Dunn's test. Significance was determined at $\mathrm{P}<0.05$.

\section{Results}

In the DES-IR group, there was an isolated lung preparation in which edema fluid appeared in a tracheal tube before the flow velocity reached $30 \mathrm{ml} / \mathrm{kg} / \mathrm{min}$ at the time of reperfusion. In this preparation, it was impossible to measure the $\mathrm{R}_{\mathrm{t}}, \mathrm{P}_{\mathrm{AW}}$, and lung weight gain after reperfusion.

\section{Coefficient of filtration}

The $\mathrm{K}_{\mathrm{fc}}$ values at $60 \mathrm{~min}$ after reperfusion were $0.40 \pm 0.13 \mathrm{ml} / \mathrm{min} / \mathrm{mmHg} / 100 \mathrm{~g}$ in the DES-IR group, $0.26 \pm 0.07 \mathrm{ml} / \mathrm{min} / \mathrm{mmHg} / 100 \mathrm{~g}$ in the IR group, and $0.22 \pm 0.08 \mathrm{ml} / \mathrm{min} / \mathrm{mmHg} / 100 \mathrm{~g}$ in the Cont group. In the DES-IR group, the $\mathrm{K}_{\mathrm{fc}}$ at $60 \mathrm{~min}$ after reperfusion was significantly higher than in the IR $(P<0.05)$ and Cont $(\mathrm{P}<0.01)$ groups. It was significantly higher than the baseline $(\mathrm{P}<0.0001)$ (Fig. 1).

\section{Wet-to-dry weight ratio}

The W/D ratios were $12.2 \pm 3.3$ in the DES-IR group, $9.3 \pm 0.9$ in the IR group, and $7.8 \pm 1.1$ in the Cont

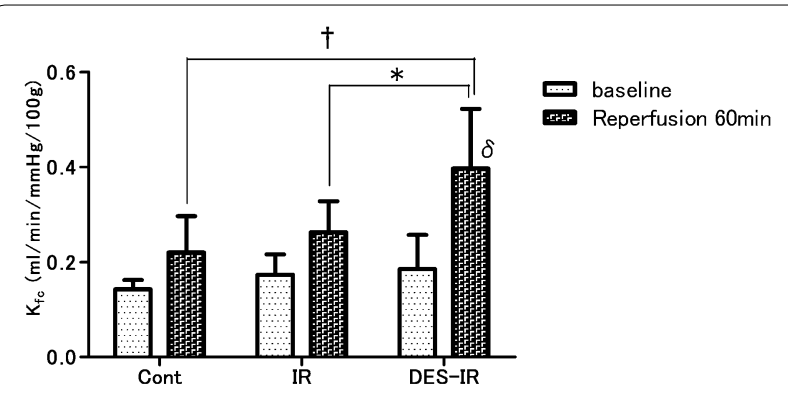

Fig. 1 Changes in the coefficient of filtration $\left(K_{\mathrm{fc}}\right)$. Data are mean \pm SD $\left(n=6\right.$ per group). ${ }^{\delta} P<0.0001$ versus baseline. ${ }^{*} P<0.05$ versus DES-IR group. ${ }^{\dagger} \mathrm{P}<0.01$ versus DES-IR group group. In the DES-IR group, the W/D was significantly higher than in the Cont group $(\mathrm{P}<0.01)$ (Fig. 2).

\section{Physiological parameters analysis}

The DES-IR group consisted of 5 isolated lung preparations, and the other two groups consisted of 6 each.

In the DES-IR group, the lung weight gain at 10, 20, $30,40,50$, and 60 min after the start of reperfusion was significantly higher than in the Cont group $(\mathrm{P}<0.05$, $\mathrm{P}<0.01, \mathrm{P}<0.001, \mathrm{P}<0.001, \mathrm{P}<0.0001$, and $\mathrm{P}<0.0001$, respectively). In this group, the lung weight gain at 20 , $30,40,50$, and $60 \mathrm{~min}$ after the start of reperfusion was significantly higher than the baseline $(\mathrm{P}<0.01, \mathrm{P}<0.001$, $\mathrm{P}<0.001, \mathrm{P}<0.0001$, and $\mathrm{P}<0.0001$, respectively) (Fig. 3a).

In the DES-IR group, the $\mathrm{R}_{\mathrm{t}}$ at $10 \mathrm{~min}$ after reperfusion was significantly higher than in the Cont group $(P<0.0001)$. In the DES-IR and IR groups, there were significant increases in $R_{t} 10$ min after reperfusion in comparison with the baseline $(\mathrm{P}<0.0001$, and $\mathrm{P}<0.01$, respectively) (Fig. 3b).

In the DES-IR group, the $\mathrm{P}_{\mathrm{AW}}$ at $20,30,40,50$, and 60 min after the start of reperfusion was significantly higher than in the Cont group $(\mathrm{P}<0.05, \mathrm{P}<0.01, \mathrm{P}<0.01$, $\mathrm{P}<0.01$, and $\mathrm{P}<0.01$, respectively). In this group, the $\mathrm{P}_{\mathrm{AW}}$ at $60 \mathrm{~min}$ after the start of reperfusion was significantly higher than the baseline $(\mathrm{P}<0.05)$ (Fig. 3c).

\section{Bronchoalveolar lavage fluid analysis}

The NO metabolite concentrations in BALF were $11.0 \pm 4.0 \mu \mathrm{M}$ in the DES-IR group, $5.2 \pm 1.3 \mu \mathrm{M}$ in the IR group, and $6.5 \pm 2.7 \mu \mathrm{M}$ in the Cont group. In the DES-IR group, the BALF concentrations of NO metabolites were significantly higher than in the Cont and IR groups ( $\mathrm{P}<0.05$, and $\mathrm{P}<0.01$, respectively) (Fig. 4).

In the DES-IR group, the BALF concentration of LDH was significantly higher than in the other groups

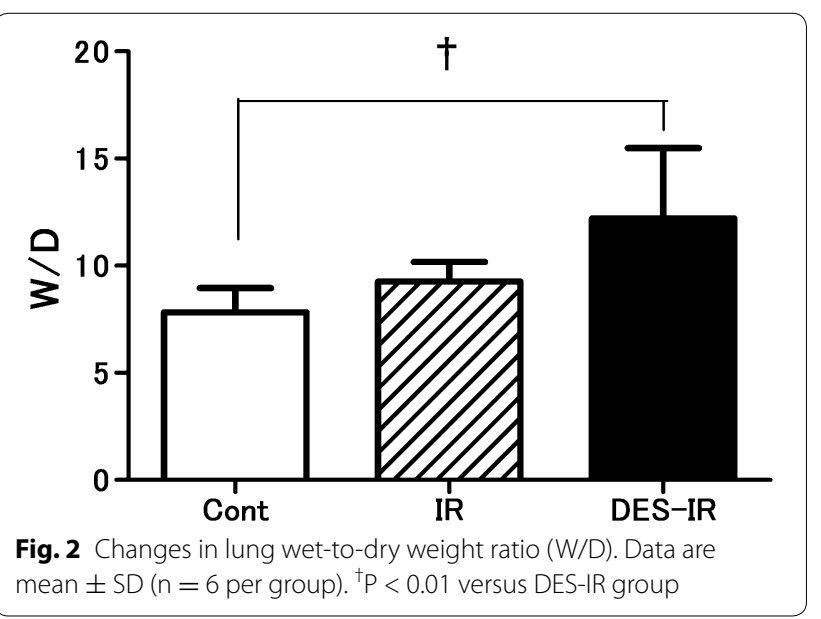



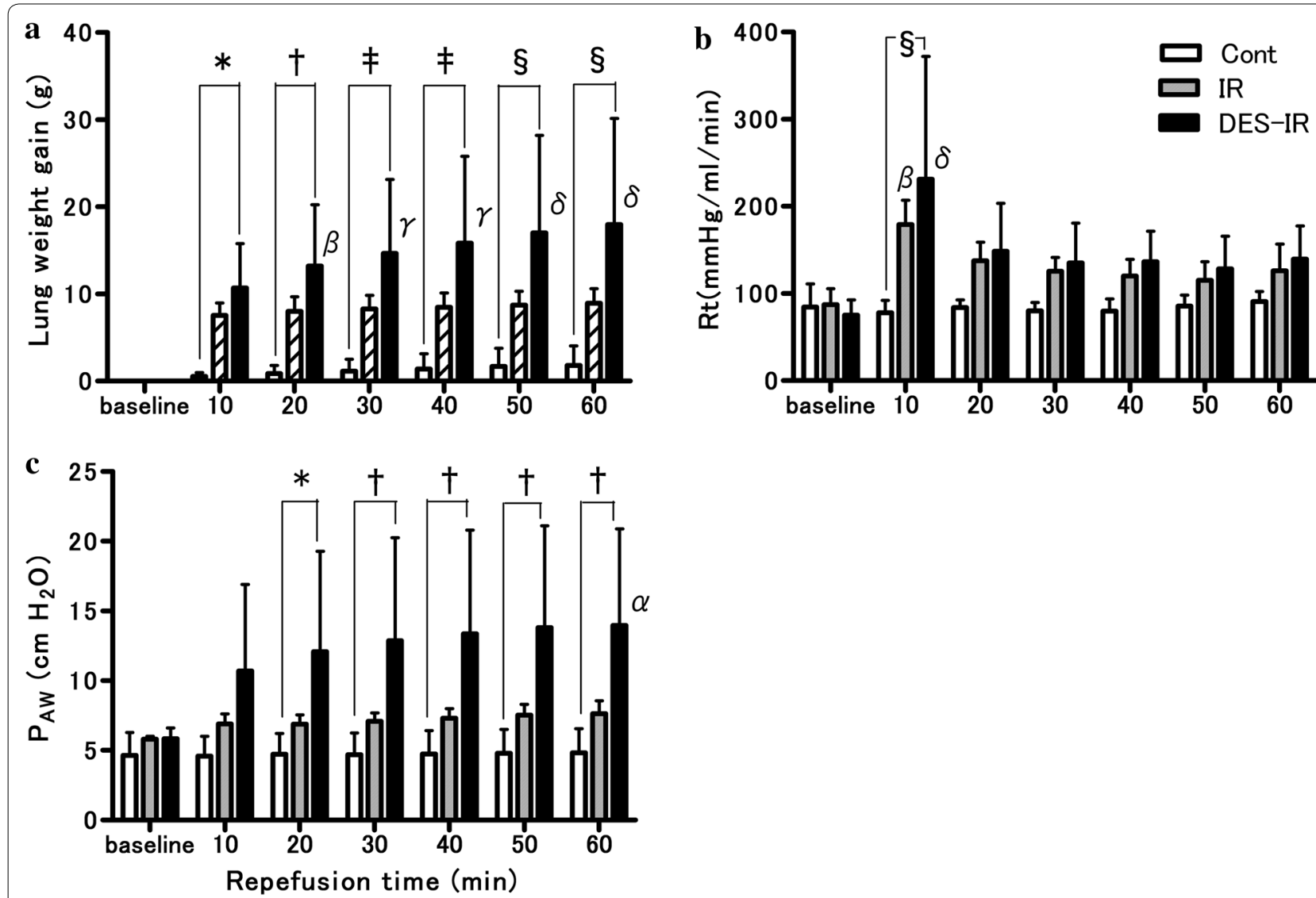

Fig. 3 Physiological parameters after reperfusion ( $n=6$ per group). One of six experiments in the DES-IR group was terminated because of severe lung edema within $10 \mathrm{~min}$ after the start of reperfusion. Therefore, the data from this animal were removed from the analysis. Data are mean \pm SD. a Lung weight gain. $\mathbf{b} \mathrm{R}_{\mathrm{t}}$ : total pulmonary vascular resistance. $\mathbf{C} \mathrm{P}_{\text {Aw: }}$ : airway pressure. ${ }^{*} \mathrm{P}<0.05$ versus Cont group. ${ }^{\dagger} \mathrm{P}<0.01$ versus Cont group. ${ }^{\ddagger} \mathrm{P}<0.001$ versus Cont group. ${ }^{{ }^{P}} \mathrm{P}<0.0001$ versus Cont group. ${ }^{a} \mathrm{P}<0.05$ versus baseline. ${ }^{\beta} \mathrm{P}<0.01$ versus baseline. ${ }^{\gamma} \mathrm{P}<0.001$ versus baseline. ${ }^{\delta} \mathrm{P}<0.0001$ versus baseline

$(\mathrm{P}<0.05)$. In all samples of BALF belonging to the Cont and IR groups, the concentrations of LDH were below the detection limit (Fig. 5).

The SOD activity in BALF was $3.8 \pm 1.1 \mathrm{U} / \mathrm{ml}$ in the DES-IR group, $4.0 \pm 1.2 \mathrm{U} / \mathrm{ml}$ in the IR group, and $3.9 \pm 1.2 \mathrm{U} / \mathrm{ml}$ in the Cont group. There were no significant differences in SOD activity in BALF among the three groups (Fig. 6).

In all samples of BALF belonging to the three groups, the BALF concentrations of IL- 6 were below the detection limit (Fig. 7).

The total amounts of VEGF in BALF were $6.5 \pm 4.3 \mathrm{ng}$ in the DES-IR group, $3.5 \pm 1.3 \mathrm{ng}$ in the IR group, and $2.0 \pm 1.0 \mathrm{ng}$ in the Cont group. In the DES-IR group, the total amount of VEGF in BALF was significantly higher than in the Cont group $(\mathrm{P}<0.05)$. It was slightly higher than in the IR group, although there was no statistical difference (Fig. 8).

\section{Discussion}

Using isolated/perfused rabbit lungs, we examined the influence of desflurane on lungs with ischemia-reperfusion injury. In the DES-IR group, $\mathrm{K}_{\mathrm{fc}}$ at $60 \mathrm{~min}$ after the start of reperfusion was significantly higher than the baseline. It was also significantly higher than in the other groups. In addition, W/D in the DES-IR group at the completion of this experiment was significantly higher than in the Cont group. Furthermore, the BALF concentrations of NO metabolites were also significantly higher than in the other groups. In the DES-IR group, the total amount of VEGF in BALF was significantly higher than in the Cont group.

The mechanism of neurogenic pulmonary edema involves the marked enhancement of the sympathetic nerves. Kandatsu et al. (2005) reported that pre-treatment inhalation of $1.5 \%$ isoflurane exacerbated neurogenic pulmonary edema in a rat in vivo neurogenic pulmonary edema model. This was because isoflurane 


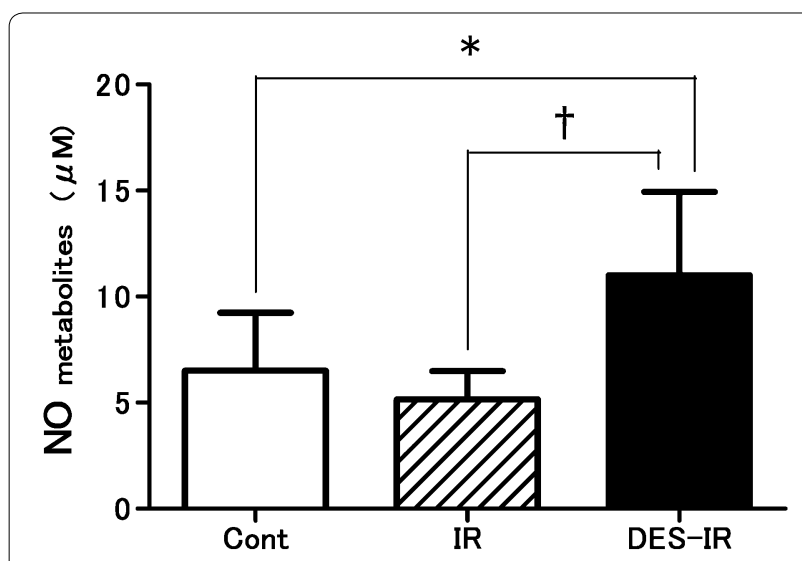

Fig. 4 Changes in nitric oxide (NO) metabolite (sum of nitrite and nitrate) concentrations in bronchoalveolar lavage fluid (BALF). Data are mean $\pm S D\left(n=6\right.$ per group). ${ }^{*} P<0.05$ versus DES-IR group. ${ }^{\dagger} P<0.01$ versus DES-IR group

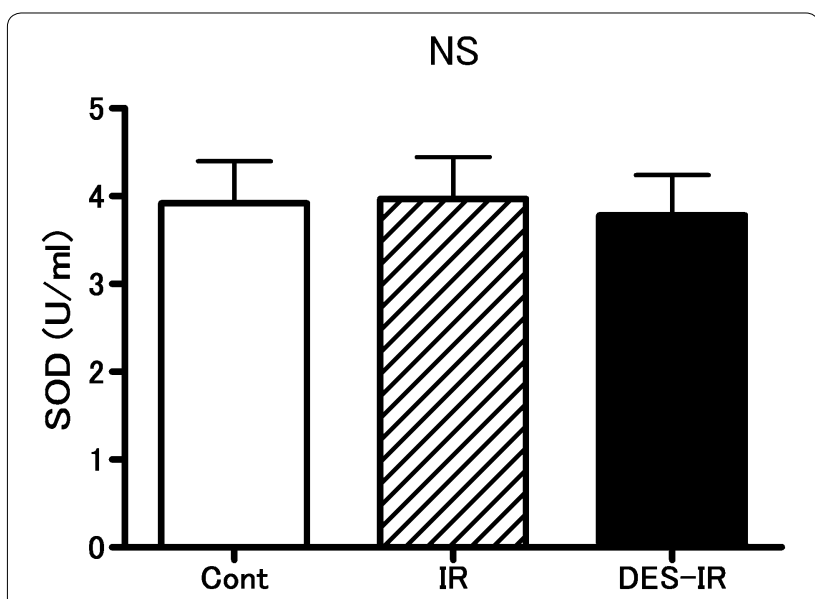

Fig. 6 Changes in superoxide dismutase (SOD) activity in bronchoalveolar lavage fluid (BALF) ( $n=6$ per group). Data are mean $\pm S D$. There were no significant differences among the three groups (NS not significant)

Desflurane is a halogenated methyl ethyl ether, similar to isoflurane. The structural formulae of desflurane and isoflurane differ in the halogen atom bound to the $\alpha$ carbon atom of the ethyl group, which chlorine in isoflurane and fluorine in desflurane (Eger 1987). Isoflurane and desflurane have common characteristics, such as concentration-dependent sympathomimetic effects. In healthy adult volunteers, the sympathomimetic effects of desflurane were more marked than those of isoflurane (Weiskopf et al. 1994).

In this experiment, in the DES-IR group, vascular resistance after reperfusion was high, and the total weight of VEGF in BALF was significantly higher than in the Cont group, and slightly higher than in the IR group. In addition, the concentrations of NO metabolites in BALF were higher than in the other groups. In addition, the pre-inhalation of desflurane potentiated ischemiareperfusion injury-related pulmonary vascular hyperpermeability. This was possibly because desflurane induced the release of VEGF by pulmonary vascular endothelial cells through a mechanism similar to that of isoflurane.

We used the release of LDH into the BALF as an estimate of cell damage during the experiment. At the completion of this experiment, the BALF concentration of LDH in the DES-IR group was higher than in the other groups. This indicated not only the decreased functions of the vascular endothelium, but also damage to lung tissue (Nielsen et al. 1998).

Kandatsu et al. (2005) reported that the pre-inhalation of $1.5 \%$ isoflurane exacerbated neurogenic pulmonary edema by inducing the release of VEGF in vascular endothelial cells in a rat in vivo neurogenic pulmonary edema model, whereas pre-inhalation of 


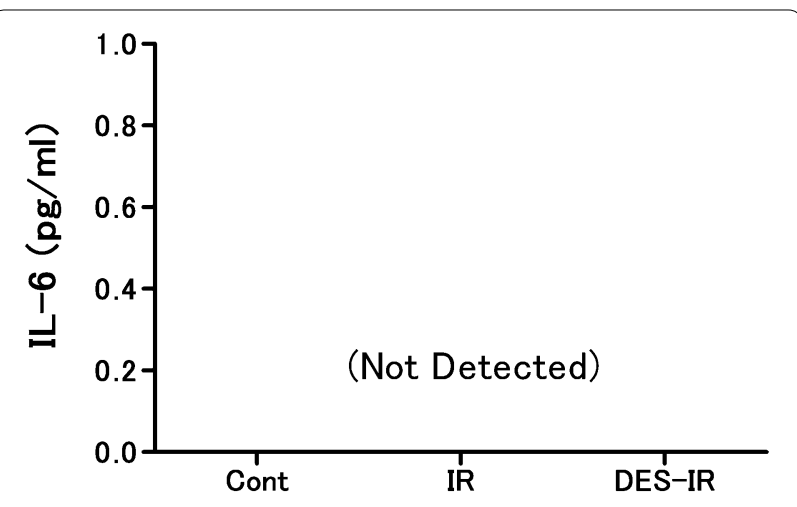

Fig. 7 Changes in interleukin (IL)-6 concentration in bronchoalveolar lavage fluid (BALF). Data are mean \pm SD ( $n=6$ per group). IL- 6 concentrations in all samples of BALF from the three groups were less than detection level

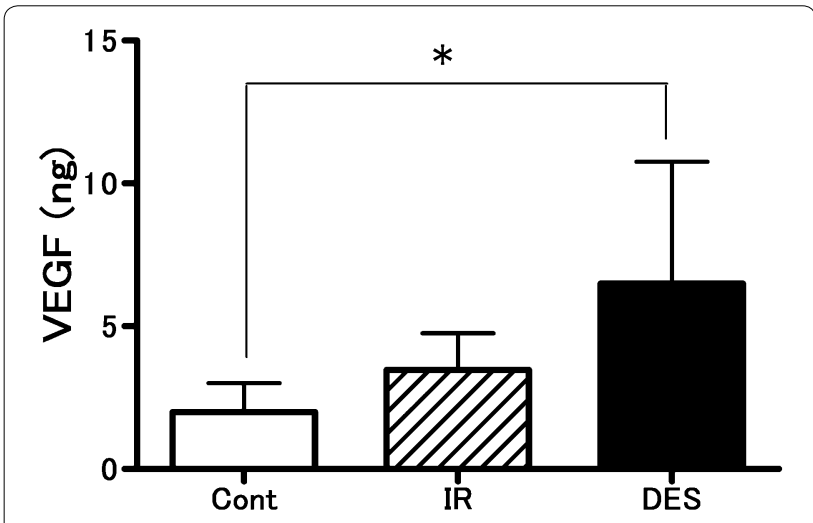

Fig. 8 Changes in total amount of vascular endothelium growth factor (VEGF) in bronchoalveolar lavage fluid (BALF). Data are mean $\pm S D$ ( $n=6$ per group). ${ }^{*} P<0.05$ versus DES-IR group

$2.5 \%$ sevoflurane reduced pulmonary edema without inducing VEGF release. In a study using perfused rat lungs, the pre-inhalation of isoflurane at 1 MAC protected against pulmonary vascular hyperpermeability after warm ischemia-reperfusion, but the protective effects of isoflurane at $3 \mathrm{MAC}$ were weak (Fujinaga et al. 2006). This was possibly because isoflurane at 3 MAC inhibited cyclic guanosine monophosphate production, increasing vascular resistance at $10 \mathrm{~min}$ after ischemiareperfusion. According to another study, in pigs under mechanical ventilation, the inhalation of desflurane at 1 MAC increased the concentration of malondialdehyde (MDA) in BALF, whereas sevoflurane at $1 \mathrm{MAC}$ did not increase it (Allaouchiche et al. 2001). Volatile inhalation anesthetics have both damaging and protective effects on the lungs depending on their types and inhalation concentrations.
Several methods can be employed to quantify the microvascular damage caused by ischemia-reperfusion injury. The most reliable is a histological examination of the lungs, which allows a detailed examination of the region and extent of damage. However, this method does not provide sufficient quantitative data on the functional status of the microvascular barrier. In contrast, $\mathrm{K}_{\mathrm{fc}}$, measured in isogravimetric conditions, can be reliably and reproducibly determined in the isolated and perfused lungs of dogs, rabbits, rats, and guinea pigs. $\mathrm{K}_{\mathrm{fc}}$ has been measured in isolated and perfused lungs in studies on various reperfusion injuries and microvessels in other lung injuries (Liu et al. 2000; Thompson et al. 1997). A high $\mathrm{K}_{\mathrm{fc}}$ value reflects high capillary permeability. In the present study, $\mathrm{K}_{\mathrm{fc}}$ also corresponded to W/D.

The present study had some limitations, as described below. In this experiment using perfused rabbit lungs, the levels of IL-6 in BALF in the three groups were below the detection limit. Kotani et al. reported that volatile inhalation anesthetics increased the BALF levels of tumor necrosis factor- $\alpha$ and macrophage inflammatory protein 2 , as an inflammatory cytokine, in rats on mechanical ventilation, whereas the BALF level of IL-6 was below the detection limit, showing no change (Kotani et al. 1999). Chung et al. (2013) indicated that the homogenized lung tissue level of IL- 6 increased using a rat lipopolysaccharide-induced lung injury model. IL-6 is released by macrophages, lymphocytes, vascular endothelial cells, fibroblasts, and mast cells (Liu et al. 2007). It may have been necessary to measure the lung tissue level of IL- 6 in this experiment. In our experiment, the SOD activity in BALF remained unchanged even after desflurane inhalation. In an in vivo experiment with rabbits, desflurane (1 MAC) inhalation enhanced pulmonary vascular permeability by oxidants released by the transient blocking of the thoracic aorta and reduced the ascorbic acid content in lung tissue (Nielsen et al. 1998). Ascorbic acid is a biological antioxidant. In pigs under artificial respiration, desflurane $(1 \mathrm{MAC})$ inhalation resulted in oxidative stress in the lungs, induced the apoptosis of lung cells, and increased the MDA concentration in BALF, but caused no change in SOD activity (Allaouchiche et al. 2001; Kalimeris et al. 2011). In this experiment with rabbits, MDA concentrations in BALF should have been measured. In addition, Liu et al. (2000) demonstrated the protective effects of sevoflurane on ischemia-reperfusion injuries of isolated perfused lungs of rats, but not of rabbits. Thus, in the present study, the same experiment should have been conducted with sevoflurane. In addition, to further demonstrate that VEGF-stimulated NO release increased vascular permeability, the effects 
of desflurane on the vascular permeability of ischemiareperfusion injured lungs pretreated with NO-inhibitors, such as L-NAME, should have been examined. Furthermore, histological changes in the ischemia-reperfusion injured lungs, caused by desflurane, should have been examined.

Among volatile anesthetics, desflurane shows the most potent protective actions on cardiac muscle (Piriou et al. 2002). In cardiac surgery using cardiopulmonary bypass (CPB), desflurane may be used for myocardial protection. However, CPB poses a risk of pulmonary ischemia-reperfusion injury. Thus, the use of desflurane at a high concentration in cardiac surgery using CPB may cause lung injuries.

\section{Conclusions}

We investigated the influence of desflurane on the lungs with ischemia-reperfusion injury using isolated/perfused rabbit lungs. The pre-inhalation of desflurane exacerbated ischemia-reperfusion-induced pulmonary vascular hyperpermeability and pulmonary damage.

\begin{abstract}
Abbreviations
MAC: minimum alveolar concentration; $\mathrm{K}_{\mathrm{fc}}$ : coefficient of filtration; BALF: bronchoalveolar lavage fluid; W/D: lung wet-to-dry weight ratio; NO: nitric oxide; VEGF: vascular endothelial growth factor; ATP: adenosine triphosphate; $P_{P A}:$ pulmonary arterial pressure; $P_{L A}$ : left atrium pressure; $P_{A W}$ : airway pressure; $\mathrm{PCO}_{2}$ : partial pressure of carbon dioxide; $\mathrm{Q}$ : blood flow; $\mathrm{R}_{\mathrm{t}}$ : total pulmonary vascular resistance; $P_{I S O}$ : isogravimetric pressure; $P_{P C}$ : pulmonary capillary pressure; BW: body weight; LDH: lactate dehydrogenase; SOD: superoxide dismutase; L: interleukin; EIA: enzyme immune assay; SD: standard deviation; ANOVA: analysis of variance; MDA: malondialdehyde; CPB: cardiopulmonary bypass.
\end{abstract}

\section{Authors' contributions}

YO carried out the measurement of pulmonary $K_{\mathrm{fc}}$ and drafted the manuscript. $\mathrm{SS}$ and $\mathrm{KF}$ participated in the measurement of $\mathrm{K}_{\mathrm{fc}}$ TH and $\mathrm{YM}$ participated in the measurement of lung W/D. KY, SM, NM, RE, and MN carried out the measurement of NO metabolites, LDH, SOD, IL-6, and VEGF, respectively. AO and ST participated in the design of the study and performed the statistical analysis. YI conceived of the study, and participated in its design and coordination and helped to draft the manuscript. All authors read and approved the final manuscript.

\section{Acknowledgements}

The authors thank Dr. Naoto Okazaki for his assistance in the chemical analysis and $\mathrm{K}_{\mathrm{fc}}$ measurements.

\section{Competing interests}

The authors declare that they have no competing interests.

\section{Ethical approval}

The study was approved by the Tottori University Laboratory Animal Care Committee (Approval Number: 12-Y-47).

\section{Funding}

This study was supported by the Japan Society for the Promotion of Science [Grant-in-Aid for Scientific Research (C) 22591729].

Received: 19 March 2016 Accepted: 25 November 2016 Published online: 29 November 2016

\section{References}

Allaouchiche B, Debon R, Goudable J, Chassard D, Duflo F (2001) Oxidative stress status during exposure to propofol, sevoflurane and desflurane. Anesth Analg 93:981-985

Ambrosio G, Zweier JL, Flaherty JT (1991) The relationship between oxygen radical generation and impairment of myocardial energy metabolism following post-ischemic reperfusion. J Mol Cell Cardiol 23:1359-1374

Bhargava M, Wendt CH (2012) Biomarkers in acute lung injury. Transl Res 159:205-217

Chung IS, Kim JA, Kim JA, Choi HS, Lee JJ, Yang M, Ahn HJ, Lee SM (2013) Reactive oxygen species by isoflurane mediates inhibition of nuclear factor kappaB activation in lipopolysaccharide-induced acute inflammation of the lung. Anesth Analg 116:327-335

Cross LJ, Matthay MA (2011) Biomarkers in acute lung injury: insights into the pathogenesis of acute lung injury. Crit Care Clin 27:355-377

De Leyn PR, Lerut TE, Schreinemakers HH, Van Raemdonck DE, Mubagwa K, Flameng W (1993) Effect of inflation on adenosine triphosphate catabolism and lactate production during normothermic lung ischemia. Ann Thorac Surg 55:1073-1078 (discussion 9)

de Perrot M, Liu M, Waddell TK, Keshavjee S (2003) Ischemia-reperfusioninduced lung injury. Am J Respir Crit Care Med 167:490-511

Drake R, Gaar KA, Taylor AE (1978) Estimation of the filtration coefficient of pulmonary exchange vessels. Am J Physiol 234:H266-H274

Dvorak HF, Brown LF, Detmar M, Dvorak AM (1995) Vascular permeability factor/vascular endothelial growth factor, microvascular hyperpermeability, and angiogenesis. Am J Pathol 146:1029-1039

Egan TM (2004) Non-heart-beating donors in thoracic transplantation. J Heart Lung Transpl 23:3-10

Eger El II (1987) Partition coefficients of I-653 in human blood, saline, and olive oil. Anesth Analg 66:971-973

Fleisher LA, Beckman JA, Brown KA, Calkins H, Chaikof E, Fleischmann KE, Freeman WK, Froehlich JB, Kasper EK, Kersten JR, Riegel B, Robb JF, Smith SC Jr, Jacobs AK, Adams CD, Anderson JL, Antman EM, Buller CE, Creager MA, Ettinger SM, Faxon DP, Fuster V, Halperin JL, Hiratzka LF, Hunt SA, Lytle BW, Nishimura R, Ornato JP, Page RL, Tarkington LG, Yancy CW (2007) ACC/ AHA 2007 guidelines on perioperative cardiovascular evaluation and care for noncardiac surgery. Circulation 116:e418-e499

Fujinaga T, Nakamura T, Fukuse T, Chen F, Zhang J, Ueda S, Hamakawa H, Omasa M, Sakai H, Hanaoka N, Wada H, Bando T (2006) Isoflurane inhalation after circulatory arrest protects against warm ischemia reperfusion injury of the lungs. Transplantation 82:1 168-1174

Green LC, Wagner DA, Glogowski J, Skipper PL, Wishnok JS, Tannenbaum SR (1982) Analysis of nitrate, nitrite, and [15N]nitrate in biological fluids. Anal Biochem 126:131-138

Janero DR, Hreniuk D, Sharif HM (1991) Hydrogen peroxide-induced oxidative stress to the mammalian heart-muscle cell (cardiomyocyte): lethal peroxidative membrane injury. J Cell Physiol 149:347-364

Kalimeris K, Christodoulaki K, Karakitsos P, Batistatou A, Lekka M, Bai M, Kitsiouli E, Nakos G, Kostopanagiotou G (2011) Influence of propofol and volatile anaesthetics on the inflammatory response in the ventilated lung. Acta Anaesthesiol Scand 55:740-748

Kandatsu N, Nan YS, Feng GG, Nishiwaki K, Hirokawa M, Ishikawa K, Komatsu T, Yokochi T, Shimada Y, Ishikawa N (2005) Opposing effects of isoflurane and sevoflurane on neurogenic pulmonary edema development in an animal model. Anesthesiology 102:1182-1189

Kolocassides KG, Galinanes M, Hearse DJ (1995) Preconditioning accelerates contracture and ATP depletion in blood-perfused rat hearts. Am J Physiol 269:H1415-H1420

Kotani N, Hashimoto H, Sessler DI, Yatsu Y, Muraoka M, Matsuki A (1999) Exposure to cigarette smoke impairs alveolar macrophage functions during halothane and isoflurane anesthesia in rats. Anesthesiology 91:1823-1833

Liu R, Ishibe Y, Ueda M, Hang Y (1999) Isoflurane administration before ischemia and during reperfusion attenuates ischemia/reperfusioninduced injury of isolated rabbit lungs. Anesth Analg 89:561-565

Liu R, Ishibe Y, Ueda M (2000) Isoflurane-sevoflurane adminstration before ischemia attenuates ischemia-reperfusion-induced injury in isolated rat lungs. Anesthesiology 92:833-840

Liu KD, Glidden DV, Eisner MD, Parsons PE, Ware LB, Wheeler A, Korpak A, Thompson BT, Chertow GM, Matthay MA (2007) Predictive and pathogenetic value of plasma biomarkers for acute kidney injury in patients with acute lung injury. Crit Care Med 35:2755-2761 
Loer SA, Scheeren TW, Tarnow J (1995) Desflurane inhibits hypoxic pulmonary vasoconstriction in isolated rabbit lungs. Anesthesiology 83:552-556

Maniscalco WM, Watkins RH, D'Angio CT, Ryan RM (1997) Hyperoxic injury decreases alveolar epithelial cell expression of vascular endothelial growth factor (VEGF) in neonatal rabbit lung. Am J Respir Cell Mol Biol 16:557-567

Murohara T, Horowitz JR, Silver M, Tsurumi Y, Chen D, Sullivan A, Isner JM (1998) Vascular endothelial growth factor/vascular permeability factor enhances vascular permeability via nitric oxide and prostacyclin. Circulation 97:99-107

Nielsen VG, Baird MS, McAdams ML, Freeman BA (1998) Desflurane increases pulmonary alveolar-capillary membrane permeability after aortic occlusion-reperfusion in rabbits: evidence of oxidant-mediated lung injury. Anesthesiology 88:1524-1534

Oyanagui Y (1984) Reevaluation of assay methods and establishment of kit for superoxide dismutase activity. Anal Biochem 142:290-296

Piriou V, Chiari P, Lhuillier F, Bastien O, Loufoua J, Raisky O, David JS, Ovize M, Lehot JJ (2002) Pharmacological preconditioning: comparison of desflurane, sevoflurane, isoflurane and halothane in rabbit myocardium. $\mathrm{Br} J$ Anaesth 89:486-491
Seeger W, Walmrath D, Menger M, Neuhof H (1986) Increased lung vascular permeability after arachidonic acid and hydrostatic challenge. J Appl Physiol 61:1781-1789

Thompson JS, Kavanagh BP, Pearl RG (1997) Nitroglycerin does not alter pulmonary vascular permeability in isolated rabbit lungs. Anesth Analg 84:359-362

Ware LB, Kaner RJ, Crystal RG, Schane R, Trivedi NN, McAuley D, Matthay MA (2005) VEGF levels in the alveolar compartment do not distinguish between ARDS and hydrostatic pulmonary oedema. Eur Respir J 26:101-105

Weiskopf RB, Moore MA, Eger El II, Noorani M, McKay L, Chortkoff B, Hart PS, Damask M (1994) Rapid increase in desflurane concentration is associated with greater transient cardiovascular stimulation than with rapid increase in isoflurane concentration in humans. Anesthesiology 80:1035-1045

\section{Submit your manuscript to a SpringerOpen ${ }^{\circ}$ journal and benefit from:}

- Convenient online submission

- Rigorous peer review

- Immediate publication on acceptance

- Open access: articles freely available online

- High visibility within the field

- Retaining the copyright to your article 